\title{
Princípios da biosseguridade e sua implementação na bovinocultura leiteira
}

\author{
Principles of biosafety and its implementation in dairy cattle \\ Principios de bioseguridad y su aplicación en ganado lechero
}

Alicia Chafado Franco

ORCID: https://orcid.org/0000-0003-4935-4339 Universidade Federal de Pelotas, Brasil

E-mail: chafadoalicia@gmail.com

Rafaela da Silva Andrett

ORCID: https://orcid.org/0000-0001-6617-647X Universidade Federal de Pelotas, Brasil

E-mail: rafaelaandrett1999@hotmail.com

Diego Peres Ávila

ORCID: https://orcid.org/0000-0002-8582-5794 Universidade Federal de Pelotas, Brasil

E-mail: diiperes1@ gmail.com

Luiza Eisenhardt

ORCID: https://orcid.org/0000-0001-6696-488X Universidade Federal de Pelotas, Brasil E-mail: luiza.eisenhardt@ hotmail.com

Aliandra Ziesemer Moreira

ORCID: https://orcid.org/0000-0003-2327-5114 Universidade Federal de Pelotas, Brasil E-mail: aliandrazmoreira@gmail.com

Paola de Avila Antunes

ORCID: https://orcid.org/0000-0002-4211-882X Universidade Federal de Pelotas, Brasil

E-mail: paola.a900@gmail.com

Ana Paula Proença Timm

ORCID: https://orcid.org/0000-0002-7286-8234 Universidade Federal de Pelotas, Brasil

E-mail: anatimm39@gmail.com

Carolina Nunes Ebersol

ORCID: https://orcid.org/0000-0001-6620-5154 Universidade Federal de Pelotas, Brasil E-mail: carolinaebersol@gmail.com

Isabel de Almeida Mancini

ORCID: https://orcid.org/0000-0002-7817-7100 Universidade Federal de Pelotas, Brasil E-mail: isabelmancini@outlook.com

Eliza Moreira Piemolini

ORCID: https://orcid.org/0000-0002-6415-1567 Universidade Federal de Pelotas, Brasil

E-mail: elizapiemolini@ hotmail.com

Isadora Athaides Martinez

ORCID: https://orcid.org/0000-0002-8869-6430 Universidade Federal de Pelotas, Brasil

E-mail: Isadora.athaides.martinez@gmail

Kaline da Silveira Timm

ORCID: https://orcid.org/0000-0003-0754-5196 Universidade Federal de Pelotas, Brasil

E-mail: kalinetimm@gmail.com

Nikolas Bahr

ORCID: https://orcid.org/0000-0003-2406-292X Universidade Federal de Pelotas, Brasil

E-mail: nikolas2bahr@gmail.com

Geferson Fischer

ORCID: https://orcid.org/0000-0002-3521-395X Universidade Federal de Pelotas, Brasil E-mail: geferson.fischer@gmail.com 


\begin{abstract}
Resumo
Cada propriedade leiteira é única e possui particularidades em sua estrutura e práticas de manejo. Portanto, implementar práticas de biosseguridade é um desafio necessário à bovinocultura leiteira, visto que há muitos prejuízos provenientes de contaminações por patógenos que podem ser evitados se estas forem colocadas em prática de maneira apropriada. Assim, para fornecer ao consumidor um leite seguro e de qualidade, além de garantir a segurança dos animais, funcionários e de todos os envolvidos na cadeia produtiva, torna-se primordial conhecer os princípios de biosseguridade e geri-los dentro do sistema de produção. Cabe ao profissional responsável avaliar os riscos ou perigos envolvidos na manutenção da saúde dos animais, e a partir dessa análise compor um plano de biosseguridade direcionado a mitigação de danos sanitários ao rebanho. Para isso, é necessário não somente comprometimento e treinamento através da educação sanitária e medidas preventivas, mas também uma supervisão adequada a fim de garantir a execução do mesmo. Assim é possível o estabelecimento de sistemas de produção sustentáveis, gerando maior taxa de produtividade para o produtor, como componente mútuo, o baixo número de perdas na produção e garantia ao consumidor um produto seguro e de qualidade.
\end{abstract}

Palavras-chave: Agente infeccioso; Manejo sanitário; Produção animal.

\begin{abstract}
Each dairy property is unique and has particularities in its structure and management practices. Therefore, implementing biosafety measures is a necessary challenge for dairy cattle farming, since there are many diseases arising from pathogen contamination that can be avoided if these measures are properly put into practice. Thus, to provide the consumer with insurance and quality, in addition to ensuring the safety of animals, employees and everyone involved in the production chain, it is essential to know the principles of biosecurity and manage them in the production system. It is up to the responsible professional to assess the risks or dangers involved in maintaining the health of the animals, and from this analysis, compose a biosecurity plan aimed at mitigating health damage to the herd. For this, it is necessary not only commitment and training through health education and preventive measures, but also adequate supervision to ensure its execution. Thus, it is possible to establish sustainable production systems, generating a higher rate of productivity for the producer, as a mutual component, the lowest number of losses in production and guaranteeing the consumer a safe and quality product.
\end{abstract}

Keywords: Infectious agent; Sanitary management; Animal production.

\title{
Resumen
}

Cada propiedad lechera es única y tiene particularidades en su estructura y prácticas de manejo. Por lo tanto, implementar prácticas de bioseguridad es un desafío necesario para el ganado lechero, ya que existen muchas pérdidas por contaminación de patógenos que pueden evitarse si se ponen en práctica adecuadamente. Así, para brindar al consumidor una leche segura y de calidad, además de velar por la seguridad de los animales, empleados y todos los involucrados en la cadena productiva, es fundamental conocer los principios de bioseguridad y gestionarlos dentro del sistema productivo. Corresponde al profesional responsable evaluar los riesgos o peligros que implica el mantenimiento de la salud de los animales y, a partir de este análisis, elaborar un plan de bioseguridad destinado a mitigar los daños a la salud del rebaño. Para ello, es necesario no solo el compromiso y la formación a través de la educación en salud y las medidas preventivas, sino también una adecuada supervisión para garantizar su ejecución. Así, es posible establecer sistemas de producción sustentables, generando una mayor tasa de productividad para el productor, como componente mutuo, el bajo número de pérdidas en la producción y garantizando al consumidor un producto seguro y de calidad.

Palabras clave: Agente infeccioso; Manejo sanitario; Producción animal.

\section{Introdução}

A ampliação da produção leiteira no Brasil é uma realidade vigente (Quintão \& Galan, 2021). Diante disso, torna-se fundamental a implementação de protocolos sanitários que assegurem a saúde e a segurança na cadeia de produção. Contudo, a questão sanitária ainda é um limitante em boa parte das propriedades leiteiras, o que resulta, muitas vezes, em contaminação por patógenos que prejudicam a produção de leite em vários aspectos (Ribeiro et al., 2009; Rangel et al., 2015; Costa et al., 2020). Torna-se de veemente importância gerir e aplicar estratégias de biosseguridade específicas para cada propriedade, a fim de tornar seguro o alimento final, preservando a saúde dos animais e fortalecendo também a saúde única.

A cadeia produtiva do leite se mostra cada vez mais promissora, e a produção mundial deste produto superou a marca dos 905 milhões de toneladas em 2020, um aumento de 2\% frente a 2019 (Fao, 2021), liderada pelos Estados Unidos da América (EUA), seguido pela Índia, China e Brasil, respectivamente. Conforme levantamento do Instituto Brasileiro de Geografia e Estatística (IBGE) de 2021, a produção de leite no Brasil apresenta crescimento contínuo desde 2016, com alta 
acumulada de 9,8\%, passando de 22,7 milhões de toneladas para 24,95 milhões de toneladas em 2020. Minas Gerais é o estado líder em produção, seguido pelo Paraná e Rio Grande do Sul.

De fato, o Brasil possui o seu destaque na produção de alimentos de origem animal, possuindo reconhecimento a nível mundial. Contudo, segundo o informe de 2018 do Ministério da Saúde sobre os Surtos de Doenças Transmitidas por Alimentos (DTA) no Brasil, o leite e seus derivados representam o quarto alimento mais envolvido em surtos de DTA (Brasil, 2019). Sabe-se que a tuberculose e a brucelose são uma das principais infecções transmitidas ao homem pelo consumo de leite e seus derivados, sendo classificada a listeriose alimentar como zoonose emergente dentre os registros. (Vasconcellos \& Ito, 2011). Frente a isso, a biosseguridade consiste em um tema de extrema importância a ser abordado, discutido e, principalmente, colocado em prática nas mais diversas esferas da produção animal. Em suma, este conceito se refere às medidas tomadas para impedir a entrada de patógenos (bactérias, fungos, vírus e protozoários) e a disseminação destes no ambiente de produção, acarretando perdas econômicas, prejuízos aos produtores e danos aos animais (Pegoraro et al., 2018). Portanto, a biosseguridade representa um conceito de aplicação geral, estabelecendo segurança dos seres vivos ao reduzir os riscos de enfermidades dentro da produção e uma forte inserção na manutenção da saúde única (Sesti, 2004).

A pandemia do novo coronavírus (Covid-19) ampliou as medidas de higiene e acelerou a implantação da biosseguridade nas propriedades leiteiras, visto que, apesar dos bovinos não transmitirem este vírus em específico, são vários os agentes virais - inclusive do grupo Coronavírus - que podem acometer animais de companhia e animais produção, sendo ainda mais necessário o estabelecimento de práticas de biosseguridade (Guimarães et al., 2020). Sabe-se também que diversas doenças infecciosas humanas são advindas de animais, visto que 75\% das infecções emergentes e reemergentes tem potencial zoonótico (Silva et al., 2020). Neste sentido, se faz necessário relacionar os aspectos de segurança alimentar e controle de zoonoses e, ainda, englobar os aspectos ambientais com a finalidade de alcançar a segurança em todos os âmbitos da cadeia produtiva (OMS, 2017; Goiozo, 2019). Dessa forma, a biosseguridade se relaciona com o conceito de One Health (Saúde Única), proposto pela OMS (Organização Mundial da Saúde), destacando a importância da aplicação de suas medidas. Logo, na bovinocultura leiteira, as práticas de biosseguridade se tornam primordiais para manter a produção livre de contaminações, garantir o bem-estar e o desempenho ótimo dos animais, assim como a segurança daqueles que estão envolvidos no processo (Pegoraro et al., 2018; Goiozo, 2019). Além disso, a sua aplicação promove a redução de prejuízos causados por diversos patógenos causadores de enfermidades, evitando consequências como a diminuição na qualidade e produção do leite, perda de peso de terneiros, quedas na eficiência alimentar, bem como problemas reprodutivos - retorno ao cio, abortos, natimortos e baixos níveis de concepção (Pegoraro et al., 2018).

Levando-se em consideração estas questões, torna-se essencial traçar um plano de biosseguridade para atingir o êxito na produção de bovinos de leite, bem como em todas as demais esferas de produção animal (Sesti, 2004). Essa estratégia deve ser aplicada de maneira estrutural e operacional, isto é, além de construções físicas que contribuam para a praticidade e dinamicidade dos protocolos de biosseguridade, uma boa gestão também é necessária para atingir os objetivos propostos pelo plano (Weddle, 2017). Em vista disso, é preciso relacionar os aspectos gerais da medicina veterinária preventiva às particularidades de cada propriedade, isso porque são encontrados diferentes riscos em cada ambiente de produção, cabendo ao técnico responsável identificá-los, avaliá-los e então definir um plano de acordo com a sua realidade (Sesti, 2004; Weddle, 2017). É importante destacar que não existe um plano de biosseguridade específico que seja eficaz em todas as propriedades produtoras de leite, mas sim medidas gerais e ações básicas que podem ser estudadas e adequadas às condições individuais de cada sistema de trabalho (Pegoraro et al., 2018).

As práticas de biosseguridade podem ser divididas em externas, abrangendo práticas de controle prévio da introdução de patógenos na propriedade, e internas, que envolvem as práticas específicas para o controle da disseminação destes patógenos dentro da propriedade (Pegoraro et al., 2018). Trabalhar com estes recursos torna o sistema de produção de leite 
mais seguro aos animais, aos trabalhadores, ao produto em questão - o leite - e consequentemente, ao consumidor, cada vez mais exigente no que se refere à qualidade e segurança alimentar. A única forma de procurar "proteger” o sistema de produção leiteiro - assim como os demais - de enfermidades e prejuízos indesejados, é elaborando um plano de biosseguridade que contemple estes aspectos (Sindileite, 2016).

\section{Referencial Metodológico}

O presente trabalho foi desenvolvido de acordo com o descrito por Pereira et al. (2018) e Martins (2018) sobre revisão de literatura, utilizando a metodologia de pesquisa bibliográfica, ou seja, aquela que se baseia na análise da literatura já publicada, que apresenta o conteúdo de forma narrativa, mapeando o conhecimento já descrito sobre questão em foco.

\section{Biosseguridade Externa}

Os critérios destinados a evitar a entrada de agentes infecciosos na produção, bem como reduzir as chances de propagação, devem ser identificados através de fatores externos e conforme a individualidade de cada propriedade (Amass, 2005). Potenciais fontes de agentes infecciosos incluem animais de reposição procedentes de granjas infectadas, sêmen utilizado em inseminação artificial (IA) ou proveniente de reprodutores durante a monta natural, animais domésticos e selvagens, roedores, insetos, pássaros, ração, água, mão de obra e veículos. A entrada de pessoas externas às propriedades rurais é um risco a ser considerado, como por exemplo, técnicos que visitam vários locais sem os cuidados sanitários podem também facilitar a entrada de patógenos (por exemplo, via matéria orgânica em calçados) (Dias, 2004).

A reposição de animais em um rebanho já estabelecido configura um risco sanitário na produção leiteira, tornando de suma importância que animais advindos de outras propriedades sejam submetidos a um período de isolamento e análises. Para que assim seja realizado de forma correta, é necessário que se tenha um local adequado para realização dos exames, testes sanitários e quarentena, longe do rebanho da propriedade e com as devidas barreiras sanitárias (Biagiotti, 2016). As análises desse período examinam a ocorrência de doenças, buscando tanto não introduzir animais doentes em rebanhos susceptíveis, quanto introduzir animais susceptíveis em rebanhos estabilizados para uma determinada enfermidade (Santos, 1999). Em suma, o período de isolamento serve para analisar o animal ou lote que chega à propriedade visto que podem estar em período de incubação de uma doença e ausente de sintomas aparentes, representando riscos de infectar todo o rebanho (Sachet et al., 2013).

A IA é uma tecnologia de reprodução assistida utilizada para o melhoramento genético dos rebanhos. No entanto, o uso da IA com sêmen contaminado com patógenos, como o vírus BoHV-1 pode acarretar problemas reprodutivos como falhas na concepção e abortos (Leão et al., 2013). Os critérios para a compra/aquisição de material genético baseados no rigor sanitário de sua produção é uma das práticas de biosseguridade evitando a introdução de algum agente infeccioso (Schultz et al., 1976). Além disso, a utilização de touros na monta natural também é um grande fator de risco para a transmissão de doenças como campilobacteriose, tricomonose bovina, diarreia viral bovina e alphaherpesvírus bovino (Thomas, 1999). Segundo Barcellos et al. (2008), os alimentos que chegam à propriedade podem ser importantes carreadores de patógenos, acarretando prejuízos nutricionais e sanitários aos animais do rebanho, e econômicos devido a possíveis perdas geradas a partir do armazenamento de maneira inadequada. Considerando a possibilidade de uma transmissão indireta dos patógenos para os animais, pode-se destacar uma relação importante entre umidade relativa do ar e do local de armazenamento e transporte (Amass, 2005). Regiões mais frias tendem a ser ambientes mais úmidos, o que favorece a multiplicação de agentes na ração caso o ambiente de armazenamento esteja com uma umidade elevada. O contrário também é verdadeiro: lugares de clima quente geralmente são mais secos, e, caso o local de transporte e armazenamento não tenha um teor ajustado de umidade, isso irá favorecer a multiplicação microbiana (Amass, 2005). Portanto, tendo em vista que umidade e temperatura do local, tempo 
de armazenamento e condições sanitárias dos alimentos transportados para a propriedade tem papel chave na disseminação de doenças para os plantéis, é imprescindível que haja um controle das condições ótimas de armazenamento referente a cada propriedade, sendo considerado um ponto crítico nas auditorias de biosseguridade (Lazzari, 1997; Barcellos et al., 2008). Os caminhões de ração que chegam à propriedade precisam ter seus carregamentos inspecionados, atuando como medida profilática na disseminação de agentes patogênicos para dentro da propriedade que possam gerar prejuízos ao rebanho bovino.

Em relação à circulação de veículos que chegam de fora da propriedade, sejam eles de carregamento de alimentos e insumos ou transporte de animais e de tratadores, é indispensável a adoção de um protocolo de circulação (Sesti, 2005). O tráfego deve ser baseado na divisão de áreas consideradas sujas e áreas consideradas limpas, de modo que os veículos cheguem por uma área central e distante da área de produção e sejam encaminhados para um local onde irão ser realizados todos os protocolos de desinfecção e sanitização, incluindo rodolúvio, pedilúvio, banho de funcionários e uso de roupas específicas para pessoas que irão trabalhar no plantel (Sesti, 2000; Barcellos et al., 2008). A partir disso, poderão circular apenas em locais considerados livres de patógenos e contaminação (também chamadas “áreas limpas”), levando ao acesso às localidades do sistema produtivo propriamente dito. Sugere-se, em propriedades que adotam práticas de biosseguridade, que as pessoas responsáveis pelos veículos usados apenas para transporte de insumos e ração não tenham acesso aos animais ou funcionários do local, mantendo um acesso restrito (Barcellos et al., 2008).

Além disso, os meios de transporte devem ser utilizados apenas para sua determinada finalidade, não havendo contato entre os veículos. Antes e depois do uso, cada um dos automóveis deve receber a devida lavagem, com um período de exposição ao sol para que a descontaminação possa ser considerada completa (Dee et al., 2016). Terapias com gás de ozônio são promissoras, se revelando como uma alternativa atraente de grande potencial na biosseguridade leiteira e já estão sendo utilizadas na suinocultura (Marino et al., 2018). Água ozonizada pode ser utilizada em diversas superfícies, inclusive na desinfecção (externa) de pessoas visitantes, carros e caminhões. Foi verificada a eficácia do uso da água ozonizada contra biofilmes bacterianos em superfícies de aço inoxidável, matando bactérias patogênicas como Listeria monocytogenes e Staphylococcus aureus (Marino et al., 2018).

Ao se tratar de mão-de-obra, as pessoas que atuam diretamente na atividade de manejo e ordenha são os produtores e colaboradores contratados. As roupas e calçados adequados com a atividade realizada devem fazer parte da rotina dessas pessoas logo ao adentrar a propriedade. Quanto ao ingresso de pessoas na propriedade, os principais EPIs (equipamentos de proteção individual) são botas, macacões e aventais, que devem ser utilizados somente no local, além de sempre higienizados e substituídos periodicamente ou sempre que houver necessidade. Dessa forma evita-se a disseminação de patógenos na propriedade e entre propriedades distintas, pois os EPIs são grandes aliados da biosseguridade tanto externa quanto interna (Pegoraro et al., 2018).

Segundo Pegoraro et al. (2018), para que todas as normas de biosseguridade estabelecidas sejam cumpridas, é importante que haja avisos pela propriedade, tanto na área externa, como nos locais de produção, sejam eles de restrição ao ingresso/permanência ou de caráter informativo, de forma que elucide aos visitantes a importância do cumprimento das regras da biosseguridade externa e como ela auxilia para uma melhor produção. A informação é um grande aliado ao sucesso no programa de biosseguridade, logo, além de visitantes, proprietários e funcionários também devem estar a par de todas as normas e da importância da execução. A Figura 1 resume as principais práticas de biosseguridade externa que devem ser adotadas em propriedades leiteiras. 
Figura 1. Práticas de biosseguridade externa aplicadas em propriedades leiteiras.

\section{Medidas de biosseguridade Externa}

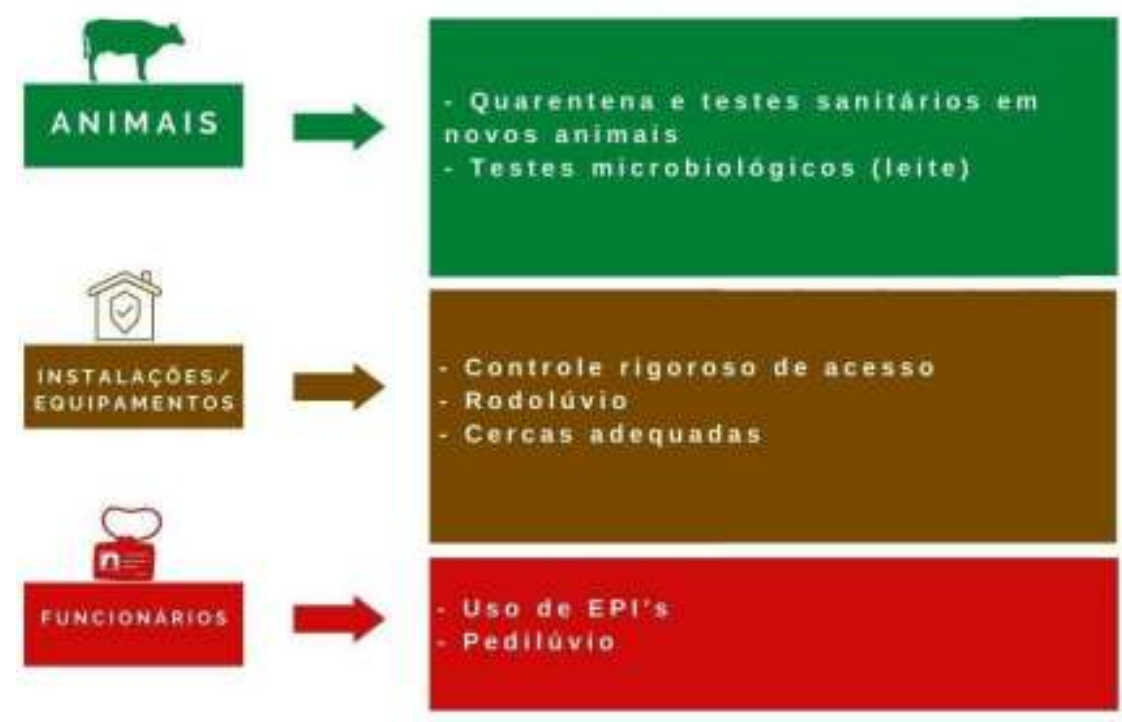

Fonte: Pegoraro et al. (2018).

\section{Biosseguridade Interna}

A atividade leiteira é influenciada pela união de vários fatores que tornam esta cadeia produtiva complexa, com condições climáticas e zootécnicas que devem ser levadas em consideração (Del Fava et al., 2003). Logo, as práticas de biosseguridade aplicadas ao manejo dentro da propriedade assegurarão a obtenção do leite de qualidade e seguro para o consumidor, preservando o meio ambiente e proporcionando bem-estar animal (Sindileite, 2016). Práticas de biosseguridade interna adotadas em propriedades leiteiras estão representadas resumidamente na Figura 2.

O manejo correto dos bovinos de leite está entre os elos mais importantes do plano de biosseguridade, é necessário manejar os animais de acordo com cada fase de desenvolvimento e de vida produtiva, a fim de que estes se mantenham saudáveis e atuem com máxima eficiência funcional (Pegoraro et al., 2018; Sindileite, 2016). Cada categoria animal possui particularidades a serem consideradas, por isso é de suma importância que os lotes sejam corretamente separados, além da higiene adequada das instalações e equipamentos - que abrangem camas, bebedouros, cochos, áreas de espera, áreas de ordenha, entre outras (Laredo et al., 2020). É fundamental utilizar um sistema de identificação individual dos animais, inspecionando de forma regular os lotes a fim de detectar quaisquer sinais de doença - sendo necessário atender rapidamente e de forma adequada os animais não sadios. Fornecer aos animais alimentação e água de fontes saudáveis, garantindo a qualidade e a quantidade ideais para cada categoria também é imprescindível (Fao, 2013).

Considerando a categoria de animais mais jovens, os bezerros recém-nascidos, se comparados aos animais adultos, são imunologicamente deprimidos e, por isso, suscetíveis a uma variedade de fatores microbianos aos quais ainda não desenvolveram imunidade. Por esse motivo, ofertar corretamente o colostro para recém-nascidos é uma prática de manejo de extrema importância no sistema de produção leiteira (Laskoski \& Albuquerque, 2020). Sabe-se que durante a gestação não há passagem de anticorpos e células de defesa da vaca para o terneiro, pois a placenta dos ruminantes é distinta dos outros mamíferos - classificada, quanto à comunicação com a circulação materna como epiteliocorial (Mota, 2013). Em vista disso, o fornecimento de colostro nas primeiras horas de vida, visando proteger o animal contra diversos tipos de infecção, é essencial a 
transferência dessas imunoglobulinas ao bezerro recém-nascido tem o papel de estabelecer a imunidade passiva até que o seu organismo consiga produzir seus próprios anticorpos, o que deve acontecer de 4 a 6 semanas de vida (Camargos, 2020).

É prática comum em várias propriedades o banco ou estoque de colostro (oriundo de vacas com saúde certificada), onde o colostro é armazenado e congelado para uso posterior (Pegoraro et al., 2018). Visto que o colostro não possui valor comercial para os produtores ou para indústria, geralmente seu excedente é desperdiçado. Contudo, uma alternativa válida para utilizar este colostro remanescente consiste na técnica de formação da silagem de colostro (Andrade et al., 2010). Este produto consiste na conservação do colostro com ausência de oxigênio, ou seja, submetido a fermentação anaeróbica, sendo este utilizado - sob armazenamento correto - para diminuir os custos com aleitamento das crias e contribuindo significativamente com a nutrição dos animais (Saalfeld, 2013). Ainda, a silagem de colostro pode ser uma alternativa em casos em que o status sanitário da vaca não é assegurado, sendo feita a técnica de silagem antes de fornecer o colostro ao neonato (Pegoraro et al, 2018).

Ainda quanto à categoria de bovinos jovens, as instalações de qualidade são um importante fator para o sucesso da criação de terneiras, bem como fornecer o mínimo de conforto térmico e físico, além de priorizar boas condições de higiene e sanidade (Bittar \& Ferreira, 2009). A maior parte das fazendas possui bezerreiros com casinhas ou baias enfileiradas, geralmente agrupadas por idade, com ventilação adequada, acesso à água e alimentos de qualidade, controle de ectoparasitas e endoparasitas, temperatura e umidade apropriadas (Paul \& Biagiotti, 2015; Martins et al., 2016). Caso o abrigo disponha de cama, esta deve ser mantida limpa e seca, sendo feita a retirada periódica de fezes e restos de alimentos. Após a saída de cada animal, o local deve ser desinfetado e as casinhas colocadas em um novo lugar (Bittar \& Ferreira, 2009). Compreendida a importância do manejo correto das instalações na criação de bovinos, vale destacar a necessidade de locais específicos para a ocorrência dos partos, isto é, piquetes ou baias maternidade, que além de secos, limpos e bem ventilados, devem ser construídos próximos aos currais e serem de fácil acesso e visualização (Pegoraro, 2018). Entre os objetivos destas instalações estão facilitar o manejo das vacas próximas à parição - proporcionando bem-estar e conforto através de acesso apropriado ao alimento, água e sombra - e possibilitar um controle adequado dos terneiros aos nascer, monitorando, por exemplo, a ingestão ideal do colostro (Vieira, 2014). O projeto EPIREP realizado pela Embrapa e instituições parceiras revelou a importância de determinados fatores de risco, entre eles, o piquete maternidade com manejo incorreto (Souza et al., 2017). O manejo incorreto se torna fator de risco visto que, doenças parasitárias como a Neosporose (causada pelo protozoário Neospora caninum cujo hospedeiro intermediário e definitivo são, respectivamente, bovinos e canídeos) são transmitidas através do acesso de cães a fetos e resíduos placentários de bovinos (Pegoraro et al., 2018).

O motivo das baias serem agrupadas por idade é justificável, pois terneiras mais velhas, apesar de serem saudáveis, podem incubar várias doenças. Assim, a prática de alimentar os animais mais jovens primeiro ajudará a prevenir a disseminação de doenças, pois uma das vias de transmissão mais comuns é a oral-fecal, seja por contato entre animais ou uso de utensílios (cochos, baldes) com limpeza inadequada. O isolamento de terneiras doentes é a prática ideal, optando por ter no ambiente de produção uma área hospitalar/enfermaria, evitando o carregamento de vetores de contaminação e fazendo com que esses animais possam ser tratados mais eficientemente (Paul \& Biagiotti, 2015).

O fornecimento de água é uma ação importante na atividade leiteira, visto que a água pode ser veículo de agentes patogênicos e tem grande importância tanto para o consumo dos animais, quanto para a limpeza e desinfecção das instalações (Cerqueira et al. 2006). Negligenciar a qualidade da água pode, por exemplo, ocasionar no surgimento de mastites no rebanho leiteiro, acarretando no aumento da contagem de células somáticas (CCS) no leite. De acordo com Schukken et al. (1991), o risco de mastites causadas por exposição ao Staphylococcus aureus aumenta quando utiliza-se água não tratada ou quando utilizada água contaminada por coliformes na lavagem do úbere. A análise periódica da qualidade da água fornecida e limpeza de caixas d'água são medidas fundamentais que devem ser adotadas pelo produtor para garantir a produção segura de leite e 
diminuir drasticamente a possibilidade de carreamento de patógenos para dentro da propriedade por esse meio, evitando assim perdas econômicas e problemas sanitários (Cerqueira et al., 2006).

Além de investir em cuidados sanitários com os animais de produção, é imprescindível direcionar a atenção às práticas de sanitização das instalações e equipamentos da propriedade, realizando a limpeza e desinfecção periódica destes. Este tipo de cuidado está entre as boas práticas fundamentais do ambiente de produção (Pas Campo, 2005). Para a correta sanitização, ou seja, redução de patógenos em superfícies inanimadas, é preciso realizar etapas como limpeza (removendo dejetos de matéria orgânica de forma manual ou mecânica a fim de eliminar parte da carga bacteriana nestas superfícies), lavagem (etapa que conta com o auxílio de água e detergentes), enxágue (remoção do detergente utilizando água), desinfecção (aplicando o uso de substâncias químicas detergentes que são capazes de eliminar a maioria dos microrganismos em forma vegetativa) e secagem (Pegoraro et al., 2018).

O momento da ordenha exige especial atenção aos cuidados sanitários, sendo indispensável a correta higienização tanto no processo de ordenha mecânica quanto manual (Pas Campo, 2005). Propriedades leiteiras que optam por adotar uma rotina integral de sanidade na ordenha apresentam melhores índices de produção de leite se comparadas àquelas que utilizam simplesmente os procedimentos básicos e mínimos de higiene. Portanto, a decisão sobre qual metodologia de rotina a ser utilizada no manejo da ordenha terá consequências diretas sobre a qualidade do leite, sobre a efetividade da ordenha e a sanidade do úbere das vacas (Gonçalves et al., 2017).

Existem três fatores obrigatoriamente envolvidos no processo de boas práticas na ordenha: o ordenhador, o ambiente em que os animais permanecem (antes, durante e depois de realizado o processo) e a rotina aplicada, sendo primordial a harmonia entre estes fatores (Zafalon et al., 2008). O ordenhador deve ser submetido a cursos de treinamento que tornem sua mão-de-obra especializada e consciente, sendo conhecedor de todo equipamento utilizado, do comportamento dos animais, bem como de todos os princípios básicos de higiene (Fao, 2013). Quanto à sala de ordenha, esta deve ser devidamente limpa, arejada, corretamente dimensionada e, principalmente, funcional para o animal e o técnico que realiza a prática (Zafalon et al., 2008). A rotina de ordenha, além de ser praticada em local tranquilo e em horários de temperatura mais amena, deve contemplar etapas determinantes como: 1) lavagem e secagem dos tetos; 2) retirada dos primeiros jatos de leite e diagnóstico de mastite (teste da caneca de fundo preto para mastite clínica e/ou CMT para diagnóstico de mastite subclínica); 3) antissepsia dos tetos ou pré-dipping; 4) ordenha propriamente dita (observando atentamente se o nível de vácuo das teteiras está nos limites normais); 5) antissepsia dos tetos após a ordenha ou pós-dipping; 6) lavagem e higiene das instalações, utensílios e equipamentos; 7) cuidados com filtração, refrigeração e armazenamento do leite obtido na ordenha (Zafalon et al., 2008; Gonçalves et al., 2017).

Além do adequado manejo do rebanho e de obter habilidades zootécnicas, os funcionários inseridos no ambiente de produção devem fazer a utilização de EPI's, sendo este um fator básico para a manutenção da sanidade durante todo o processo (Fao, 2013). É extremamente válido que estes funcionários sejam submetidos a um Programa de Capacitação que deve ensinar, entre diversas técnicas, as boas práticas de manejo e higiene, reconhecimento e prevenção de perigos, cuidados com medicamentos e vacinas, como também primeiros socorros, limpeza/higienização/ manutenção de equipamentos (Pas Campo, 2005).

Garantir o fornecimento de alimento e água de qualidade aos animais é fundamental para obter resultados favoráveis na produção de leite, visto que os animais demandam ter suas necessidades nutricionais e fisiológicas supridas para atingir o seu máximo potencial produtivo (Pas Campo, 2005). De acordo com o código CODEX (2004) sobre as boas práticas de alimentação animal, os alimentos e os ingredientes da alimentação ofertada aos animais devem ser obtidos, transportados e mantidos em condições adequadas com o intuito de evitar possíveis contaminações por pestes, microorganismos ou substâncias químicas e físicas. Alimentos contendo substâncias indesejáveis como contaminantes ambientais e/ou industriais, agentes 
patogênicos e toxinas (micotoxinas, por exemplo), devem ser identificados, controlados e eliminados, diminuindo assim o risco de danos à saúde animal e humana (Codex, 2004). É importante obter alimentos com rastreabilidade advindos de produtores e fornecedores com programa reconhecido de garantia de qualidade, assim como informações dos tratamentos químicos realizados nos alimentos adquiridos e se os mesmos são adequados para a alimentação do rebanho (Fao, 2021). As instalações e os equipamentos envolvidos no manejo e armazenamento dos alimentos devem ser avaliados, mantidos limpos e livres de resíduos de detergentes e desinfetantes. Além disso, os cochos devem ser mantidos sempre limpos, enquanto que a água para o consumo deve ser fresca, livre de contaminantes e permanecer à disposição dos animais (Fao, 2021).

Ao longo da cadeia produtiva, não são escassos os resíduos gerados pelos diversos procedimentos realizados durante a produção do leite. São produzidos resíduos líquidos - como urina, resíduos de leite, águas remanescentes de lavagem - e resíduos sólidos, classificados como orgânicos (dejetos animais, carcaças, restos de alimentos, sementes) e inorgânicos (medicamentos vencidos, embalagens, peças e máquinas danificadas, EPIs, perfurocortantes). Assim, torna-se essencial como medida de biosseguridade interna a gestão dos resíduos gerados nas propriedades e a destinação correta de cadáveres, sendo pontos importantes para desenvolver uma produção ambientalmente sustentável - apesar de a quantidade de dejetos produzidos e os resíduos resultantes do processamento do leite consistem em uma das maiores dificuldades nos sistemas de produção (Ricardo, 2016).

O setor leiteiro no Brasil tem buscado alta produtividade e elevada concentração de animais, apontando para um aumento na produção de dejetos, sem necessariamente uma busca pela maioria dos produtores, por uma destinação correta do esterco e da urina dos animais (Pohlmann, 2000). Em confinamentos de animais leiteiros, há a produção de cerca de 9,0 a 12,0\% do peso vivo de efluentes orgânicos por dia (Campos et al., 2002). Sabe-se que a elevada produção de resíduos na bovinocultura leiteira e o direcionamento dos mesmos nos corpos de água e no solo de forma indevida, causam problemas e contaminações ambientais (Campos, 1997). Sendo um dos grandes desafios dos sistemas de produção, as propriedades leiteiras devem dispor de um sistema apropriado de destino e tratamento de resíduos, dejetos e carcaças que respeitem as normas ambientais vigentes (Fao, 2013). O Brasil, no entanto, não dispõe de uma legislação voltada para a destinação de dejetos de bovinos leiteiros no solo, porém, a utilização de dejetos como fertilizante pode ser baseada na quantidade de nutrientes referenciais, normalmente nitrogênio ou fósforo, e com o que está disponível no solo, com o tipo de cultura a ser plantada e com recomendações agronômicas (Matos, 2007). De acordo com a resolução do CONAMA nº 430/2011, os efluentes poderão ser lançados diretamente nos corpos receptores (fontes hídricas) após o devido tratamento, ficando os órgãos ambientais estaduais encarregados de fiscalizar, orientar e punir as atividades potencialmente poluidoras.

A primeira etapa de tratamento de efluentes, conhecida como tratamento preliminar, é baseada na remoção de sólidos grosseiros e areia, feita na maioria das vezes por meio de grades ou peneiras, e posteriormente pela atuação do desarenador. As etapas subsequentes removem a matéria orgânica com o intuito de acelerar os mecanismos de degradação (Von Sperling, 2005). O tratamento de tipo biológico é o mais recomendado para dejetos e águas residuárias, tendo este como base o contato entre microrganismos e material orgânico presente nos efluentes, com o intuito de convertê-lo em gás carbônico, água e alimento para os microorganismos (Campos, 1997). De acordo com Matos (2005), além da disposição controlada no solo, que é um método de disposição final e tratamento, os principais sistemas de tratamento de efluentes agroindustriais são os sistemas anaeróbios, os sistemas "wetlands" construídos e os sistemas de lagoas de estabilização.

A destinação incorreta dos cadáveres e restos de parição traz riscos para a saúde dos rebanhos, impactos ambientais, como a contaminação da água e do solo (Mauro \& Silva, 2019). Por esse motivo, após realizar a coleta de material e/ou necropsia, os resíduos de animais mortos devem ser rapidamente extinguidos, evitando o risco de contaminação à propriedade (Pegoraro et al., 2018). Em suma, existem duas estratégias de destinação: o tratamento dentro da propriedade (por práticas como compostagem acelerada, biodigestão anaeróbia, desidratação, incineração e reciclagem industrial de carcaças - 
rendering) ou remoção para centrais de tratamento (que deve ser feita de maneira cautelosa, seguindo todas as orientações de biosseguridade, por empresas oficialmente legalizadas e regulamentadas, com rastreabilidade acompanhada pelo Serviço Veterinário Oficial (Pereira, 2017). Quanto ao descarte correto, não há legislação específica no Brasil que regulamente este descarte atendendo aos aspectos sanitários e ambientais. Os métodos mais utilizados para destinação de cadáveres oriundos da pecuária são o enterro, a disposição no ambiente e a compostagem, já que são métodos de menor custo. No entanto, existem outras diferentes destinações, como a incineração, reciclagem industrial de animais, digestão anaeróbia, hidrólise alcalina e disposição no oceano (Mauro \& Silva, 2019). Ainda, sabe-se que a compostagem é o método mais indicado por consistir em uma opção ambientalmente correta, além de ser econômico à propriedade. Baseia-se na decomposição da matéria orgânica realizada por bactérias e fungos, que produz um biocomposto eficiente na produção agrícola, e surgiu como uma alternativa ao enterro, deposição em valas ou à disposição no meio ambiente, que podem causar problemas ambientais e disseminação de doenças (Otênio et al., 2010). O enterro se baseia na colocação do cadáver em uma cova, devendo sempre se evitar o contato com o lençol freático e a proximidade com fontes de água. Esse método garante a contenção de surtos de doenças e auxilia na destinação em locais possíveis de se utilizar retroescavadeiras, porém pode levar à contaminação da água subterrânea, bem como a formação de odores que podem ser atrativos para animais carniceiros (Mauro \& Silva, 2019). Vale lembrar que, caso o produtor opte por enterro, este deve ser realizado com base em todo protocolo correto (utilização de cal, cobertura correta para evitar o acesso de cães, cercamento e identificação da área) e feito com distância mínima de 50 metros das instalações e pastagens, e no mínimo 150 metros de distância das fontes de água (Pegoraro et al., 2018).

As medidas integradas de biosseguridade também contemplam o controle de vetores, visto que diversas patologias que ameaçam o bem-estar dos animais e causam prejuízos diretos e indiretos à produção podem ser transmitidas por insetos e roedores. Sendo assim, torna-se indispensável o controle destes (Pegoraro, 2018). Entre as principais pragas que afetam a produção, estão os roedores (Ibs, 2020) atraídos às propriedades principalmente pela disponibilidade de água, restos de ração nas baias e espaços para criarem seus ninhos. Por isso, é de extrema necessidade o controle desses vetores, uma vez que podem contaminar e transmitir variadas doenças na propriedade leiteira (Sesti, 2005). Para isso, utiliza-se uma metodologia baseada em algumas fases, sendo elas: 1) a inspeção da propriedade infestada; 2) a identificação dos roedores presentes e suas particularidades; 3) medidas corretivas de problemas de manejo na propriedade que atraem e permitem a entrada desses roedores à produção (como lixo, entulho, danos estruturais); 4) medidas preventivas (como edificações, defesas estruturais e barreiras físicas à prova de roedores); 5) a desratização com o uso de armadilhas e/ou raticidas; e 6) a avaliação e o monitoramento para impedir outras infestações (Pegoraro et al., 2018).

Além de precauções contra roedores, sabe-se que os insetos representam um dos maiores desafios a serem combatidos pelos projetos de biosseguridade, além de serem responsáveis por prejuízos diretos aos animais, como lesões de pele, alergias, perda de sangue - e indiretos, como transmissão de doenças, despesas e perda de capacidade produtiva de leite (Pegoraro et al, 2018). Por isso, para um controle eficiente, devem ser levadas em conta todas as suas fases de desenvolvimento, as particularidades de cada espécie, o tipo de instalações, a resistência aos inseticidas, e até mesmo a topografia da região. As moscas, por sua vez, podem transmitir doenças de variadas formas, seja pela ingestão/eliminação de patógenos pelas fezes, pela ação de hematofagia, pelo regurgitamento ou pela dispersão de germes nos alimentos pelas patas, asas e parte do aparelho bucal (Ibs, 2020). Logo, o controle de moscas pode ser realizado com a sanidade da propriedade e destinação correta do esterco, com a utilização de inseticidas residuais em partes das instalações, com inseticidas nos animais a partir de imersão, aspersão, pour on, spot-on, brincos ou colares, ou com armadilhas atrativas com feromônios ou com cola entomológicas (Pegoraro, 2019). Na figura 2, são observadas as medidas de biosseguridade interna aplicadas em propriedades leiteiras. 
Figura 2. Práticas de biosseguridade interna aplicadas em propriedades leiteiras.

\section{Medidas de biosseguridade Interna}

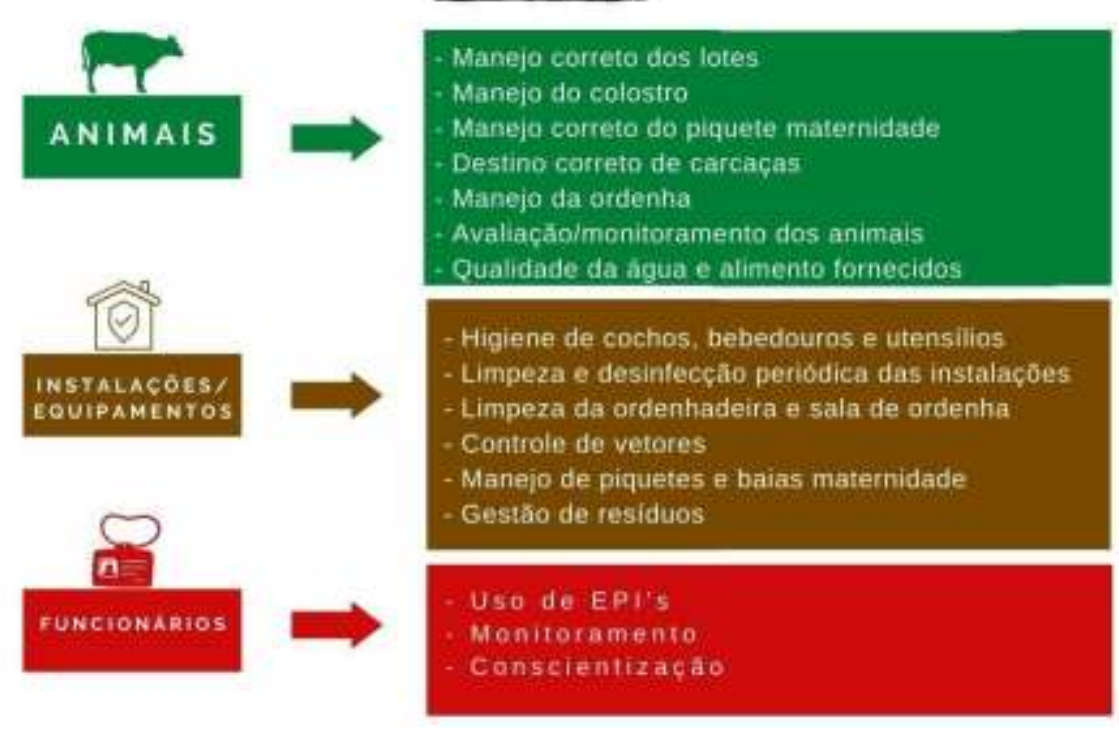

Fonte: Pegoraro et al. (2018).

\section{Plano e Gestão de Biosseguridade}

O plano de biosseguridade deve ser traçado de acordo com as características de cada propriedade, baseando-se nas enfermidades que causam maior impacto na mesma, ou então nas enfermidades em que há maior risco de aquisição, sempre respeitando a capacidade física e financeira da propriedade e do produtor. Além disso, o técnico deve realizar a análise de riscos ou perigos, e a partir destes elaborar um plano estratégico direcionado a mitigar os principais danos (Jansen et al., 2009; Moore et al., 2011). Para implementar o plano de forma eficiente e rentável, é preciso ter em mente alguns pontos chaves dentro de biosseguridade externa, como apresentado na Figura 1, para que haja um controle da entrada de agentes patogênicos na propriedade, e também de biosseguridade interna, como apresentado na Figura 2, para controlar a disseminação destes agentes (Pegoraro et al., 2018). Deve-se levar em consideração, também, que cada sistema de produção leiteira é único e possui particularidades em seu conjunto de estruturas e manejo. Visto isso, cabe ao técnico elencar a problemática de cada sistema para que seja traçada a melhor estratégia para eliminar fatores de risco, objetivando um ambiente mais seguro no âmbito sanitário (Durr, 2005). Portanto, o profissional responsável deve responder algumas questões para elaborar o melhor plano para o laticínio em foco: Onde está localizada a propriedade (como é o clima, o relevo, a vegetação e os acessos)? Como é o calendário sanitário? Qual sistema de criação? Quais doenças que incidem nesta região? Qual a quantidade de animais? Quais as categorias de animais presentes? Qual a produção de leite diária das vacas? Qual a CCS da propriedade? Como é feito o manejo dos animais? Com quais estruturas a propriedade conta? Se há funcionários, quantos? Há serviço terceirizado? Faz-se uso de EPI completo?

Após traçado um plano de biosseguridade, esse deve ser posto em prática para obtenção de sucesso, sendo necessário não somente comprometimento e treinamento através da educação sanitária e medidas preventivas, mas também uma supervisão adequada a fim de garantir a execução do plano traçado. Práticas fortalecidas asseguram não somente uma menor aplicação de medicamentos, mas um menor custo de produção e, por consequência, um melhor produto final. (Pegoraro et al., 2018). Não há práticas exatas de biosseguridade, todavia as que melhor se adequam à propriedade em questão devem ser implementadas. Alguns proprietários, por exemplo, por não terem condições de realizar a quarentena de animais recém- 
introduzidos no rebanho, optam por adquirir somente animais testados e vacinados para evitar riscos ao seu negócio. A nível reprodutivo, alguns produtores optam por realizar a compra de sêmen e realizar a IA como método eleito de reprodução a fim de eliminar os riscos de contaminação oriundos da monta natural, o que é comum se o reprodutor for emprestado de outras propriedades, ou simplesmente para eliminar o custo de adquirir um reprodutor próprio. Sendo assim, gerir as medidas dentro da propriedade é uma responsabilidade relativa e pertencente ao proprietário, já que este melhor conhece o sistema implantado (Sachet et al., 2013).

Ter animais saudáveis e produtivos e, consequentemente entregar ao consumidor um produto final seguro está intimamente relacionado a uma gestão adequada do protocolo de biosseguridade em toda a cadeia de produção leiteira. Apesar de escassos na literatura, algumas empresas apresentam exemplos de práticas de biosseguridade adotadas como forma de marketing, a fim de atrair consumidores engajados. Em 2013 foi realizada uma pesquisa sobre a implantação de certas práticas de biosseguridade em rebanhos leiteiros na agricultura familiar da região do sudoeste paranaense, onde os números revelados são preocupantes, visto que somente em $11 \%$ destas propriedades compreendia-se a importância ou praticava-se a quarentena de animais recém introduzidos. Ainda, em apenas $8 \%$ destas propriedades houve o relato da realização periódica diagnóstico de enfermidades nos animais e em menos de 50\% havia acompanhamento técnico veterinário (Sachet et al., 2013).

Contudo, os problemas de gestão e aplicação das atividades de biosseguridade não se restringem ao âmbito nacional. Dados de países como a Irlanda revelam que as propriedades possuem uma enorme discrepância quanto a quantidade de proprietários que não adotam as práticas de biosseguridade. Essa discrepância, segundo Sayers et al. (2013), está relacionada a três pilares da biosseguridade: rebanho fechado, quarentena e testagem dos novos animais adquiridos, sendo esses subutilizados. Oitenta por cento dos proprietários entrevistados não adotaram a quarentena e apenas a minoria realizou testes nos animais vindos de fora, refletindo tanto a falta de instrução e acompanhamento técnico profissional para influir na gestão, quanto no desconhecimento das atividades necessárias para a biosseguridade (Duncan, 1990; Pritchard, 1996; Davison et al., 2003). Além dos produtores não estarem cientes, em sua totalidade, sobre os exames e testes aplicados nos animais comprados e introduzidos na sua propriedade, muitos não implementam a quarentena no seu sistema de produção devido a falta de espaço disponível para a separação. Apesar disso, depois de serem conscientizados quanto ao risco da falta de práticas de biosseguridade nas propriedades, muitos dos produtores mudaram suas perspectivas a respeito desse conceito, demonstrando mais uma vez a necessidade de instrução e acompanhamento devidos para a gestão da biosseguridade leiteira (Damiaans et al. 2018).

\section{Considerações Finais}

É indiscutível a importância de implementar na bovinocultura leiteira programas sanitários e práticas de biosseguridade. Considerar a individualidade de cada propriedade é a base para a formação de um plano de ação eficaz, levando em conta os riscos individuais de exposição a agentes biológicos que podem gerar implicações coletivas e assim comprometer a qualidade da produção. Portanto, conclui-se necessário que tais medidas preventivas sejam adotadas na rotina da propriedade, estabelecendo um sistema de produção fundamentado na saúde e qualidade do rebanho, gerando maior taxa de produtividade, baixo número de perdas na produção e garantia ao consumidor de um produto seguro e de qualidade.

Para trabalhos futuros na área da biosseguridade em sistemas de produção de leite, julga-se interessante realizar pesquisas em propriedades de bovinocultura leiteira no Brasil para avaliar quão rigorosas têm sido as medidas aplicadas nestas, a fim de compreender a realidade destas práticas na rotina de produção. Traçar paralelos entre as práticas ideais e as possibilidades reais dos produtores pode ser uma ferramenta útil para compreender a situação da biosseguridade nas diversas propriedades do Brasil. 


\section{Referências}

Afalon, L. F., Pozzi, C. R., De Campos, F. P., Arcaro, J. R. P., Sarmento, P. \& Matarazzo, S. V. (2008). Boas práticas de ordenha. Embrapa Pecuária Sudeste.

Alves, R. G. O., Silva, L. O. C., Euclides Filho, K. \& Figueiredo, G. R. (1999). Disseminação do Melhoramento Genético em Bovinos de Corte. Rev. Bras. Zootec., 28 (6), 1219-1225.

Amass, S. F., Stevenson, G. W., Anderson, C., Grote, L. A., Dowell, C., Vyverberg, B. D., Kanitz, C. \& Ragland, D. (2000). Investigation of people as mechanical vectors for porcine reproductive and respiratory syndrome vírus. Journal Swine Health \& Production, 8, 161-166.

Amass, S. F. (2005). Biosecurity: Reducing the spread. The Pig Journal, 56, 78-87.

Andrade, E. A., Anselmi, R. \& Mendes, C. Q. (2010). Silagem de colostro: alternativa sustentável para a bovinocultura leiteira. Caderno Rural. 49.

Barcellos, S. N., Morais, T. J., Santi, M. \& Gheller, N. B. (2008). Avanços em programas de biosseguridade para a suinocultura. Biosseguridade.

Biagiotti, P. R. (2016). Construindo barreiras na fazenda leiteira. Revista Leite Integral. https://www.revistaleiteintegral.com.br

Bittar, E. \& Ferreira, L. (2009). Qual o melhor tipo de instalação para a minha bezerra durante o período de aleitamento? https://www.milkpoint.com.br/colunas/carla-bittar/qual-o-melhor-tipo-de-instalacao-para-a-minha-bez erra-durante-o-periodo-de-aleitamento-54019n.aspx

Brasil - Ministério da Saúde - Secretaria de Vigilância em Saúde. (2018). Surtos de Doenças transmitidas por Alimentos no Brasil. Informe.

Camargos, T. (2020). Colostro bovino e importância na colostragem de bezerros. https://prodap.com.br/pt/blog/colostro-bovino-colostragem-para-bezerrosleiteiros. Reciclagem de dejetos de bovinos em sistema intensivo de produção de leite. Ciência e Agrotecnologia, Lavras, 26 (2),.426-438.

Campos, A. T. (1997). Análise da variabilidade da reciclagem de dejetos de bovinos com tratamento biológico, em sistemas intensivos de produção de leite. Tese (Doutorado em Agronomia) - Faculdade de Ciências Agronômicas do Campus de Botucatu. Botucatu - SP.

Cardoso, T. A. O., Navarro, M. B. M. A., Soares, B. E. C. \& Tapajós, A. M. (2008). Biosseguridade e biossegurança: aplicabilidades da segurança biológica. Interciência. 33 (8), 561-568.

Carvalho, M. P. (2018). Levantamento Top 100: os 100 maiores produtores de leite no Brasil. http://www.milkpoint.com.br/top100/top100-2018.pdf

Casari, P. \& Tormen, P. (2007). Atividade leiteira,agricultura familiar e desenvolvimento regional: estudo de caso da Linha Tormem, Chapecó-SC. http://online.unisc.br/seer/index.php/cepe/article/viewFile/936/1687

Cerqueira, M. M. O. P., Picinin, L. C. A., Fonseca, L. M., Souza, M. R., Leite, M. O. \& Penna, C. F. A. M. (2006). Qualidade da água e seu impacto na qualidade microbiológica do leite. In: Mesquita, A.J., Durr, J.W., Coelho, K.O. Perspectivas e avanços da qualidade do leite no Brasil. Goiânia: Talento, 1, 273-290.

Costa, D. E. M. (1987). Desinfetantes em saúde animal. Boletim de Defesa Sanitária Animal. Ministério da Agricultura, Brasília, DF.

Costa, R. V. C., Abreu, A. P. M., Thomé, S. M. G., Massard, C. L., Santos, H. A., Ubiali, D. G. \& Brito, M. F. (2020). Parasitological and clinical-pathological findings in twelve outbreaks of acute trypanosomiasis in dairy cattle in Rio de Janeiro state, Brasil. Veterinary Parasitological: Regional Studies and Reports, $22,100-466$.

CODEX ALIMENTARIUS COMMISSION. (2004). Code of hygienic practice for milk and milk products. CAC/RCP 57.

Davison, H. C., Smith, R. P., Sayers, A. R. \& Evans, S. J. (2003). Dairy farm characteristics, including biosecurity, obtained during a cohort study in England and Wales. Cattle Practice, 11, 299-310.

Damiaans, B., Sarrazin, S., Heremans, E. \& Dewulf, J. (2018). Perception, motivators and obstacle of biosecurity in cattle production. Vlaams Diergeneeskundig Tijdschrift, 8 (3).

Da Rocha, S. S. (2011). Invisibilidade de situações de risco biológico no campo da saúde pública. Fundação Oswaldo Cruz.

Da Silva, D. M. (2018). Avaliação das práticas de manejo em granja de corte no município de Areia- PB. Práticas de manejo, $15-17$.

Del Fava, C., Arcaro, J. R. P., Pozzi, C. R., Júnior, A. I., Fagundes, H., Pituco, E. M., De Stefano, E., Okuda, L. H. \& Vasconcellos, S. A. (2003). Manejo sanitário para o controle de doenças de reprodução em um sistema leiteiro de produção semi-intensivo. Arq. Inst. Biol. São Paulo, 70 (1), 25-33.

Dias, R. O. S. (2004). Biosseguridade: por onde começar? Parte 1. http://www.milkpoint.br

Duarte, S. C., Jaenisch, F. R. F., Henn, J. D., Fortes, F. B. B. \& Nones, J. (2018). Requisitos básicos de biosseguridade para granjas de postura comercial. Embrapa Suínos e Aves.

Duncan, A. L. (1990). Health security in cattle herds. In Practice 12, 29-32.

Dürr, J. W. (2005). Estratégias para a melhoria da qualidade do leite. In: Carvalho, L.; Zoccal, R.; Martins, P. Arcuri P. B.; Moreira, M. S. Juiz de Fora, MG: Editora Embrapa, p. 89- 97.

FAO - Food and Agriculture Organization of the United Nations. (2021). Dairy Market Review: Overview of global dairy market developments in 2020. Abril.

FAO e IDF. (2013). Guia de boas práticas na pecuária de leite. Produção e Saúde Animal Diretrizes, 8. Roma. http://www.fao.org/3/ba0027pt/ba0027pt.pdf 
Guimarães, A. S., Vicentini, N. M., \& De Souza, G. N. (2020). A biosseguridade chegou nas propriedades leiteiras. https://www.milkpoint.com.br/artigos/producao-de-leite/a-biosseguridade-chegou-nas-prioridades-leit eiras-222644/

Goiozo, P. F. I. (2019). II Simpósio de Saúde Única - Rev Expressão, 88-91.

Gonçalves, J. L., Tomazi, T. \& Dos Santos, M. V. (2017). Rotina de ordenha eficiente para produção de leite de alta qualidade. Rev. Acad. Ciênc. Anim.

Heck, A. (2005). Biosseguridade na Suinocultura: Aspectos práticos. Biosseguridade, [s. 1.]. AVESUI 2006 - 25 A $27 / 04$ DE 2006 (pucgoias.edu.br)

IBGE - Instituto Brasileiro de Geografia e Estatística - IBGE. (2021). Pesquisa Trimestral do Leite. Rio Grande do Sul, RS. https://sidra.ibge.gov.br/home/leite/brasil

Instituto BioSistêmico - IBS. (2020). Medidas de Defesas Sanitárias da Propriedade: Quais adotar? Piracicaba - SP. $1^{\circ}$ edição.

Jansen, J., Borne, B. H. P., Renes, R. J., Schaik, G., Lam, T. J. G. M. \& Leeuwis, C. (2009). Explaining mastitis incidence in Dutch dairy farming: the influence of farmers' attitudes and behaviour. Prev Vet Med. 92 (3): 210-223.

Jordan, E., Dement, A. I. \& Faries JR., F. C. (2016). Biosecurity practices for dairy operations. Texas A\&M Agrilife Extension. https://texashelp.tamu.edu/wpcontent/uploads/2016/02/Biosecurity-Practices-For-Dairy-Operations. pdf

Jung, C. F. \& Matte, A. A. J. (2016). Produção leiteira no Brasil e características da bovinocultura leiteira no Rio Grande do Sul. Bovinocultura , [s. 1.]. Produção leiteira no Brasil e características da bovinocultura leiteira no Rio Grande do Sul | Matte Júnior | Ágora (unisc.br).

Laredo, A. P., Lima, L. S., Benetti, K. K. V. \& Marques, A. P. L. (2020). Medidas de biosseguridade em fazendas leiteiras.: https://www.milkpoint.com.br/artigos/producao-de-leite/medidas-de-biosseguridade-na-bovinocultura-leiteira-221221/

Laskoski, L. \& Albuquerque, M. (2020). Banco de colostro: ferramenta para a saúde das bezerras. https://www.milkpoint.com.br/artigos/producao-deleite/banco-de-colostro-uma-importante-ferrament a-para-a-saude-das-bezerras-68193n.aspx.

Lazzari, F. A. (1997). Umidade, fungos e micotoxinas na qualidade de sementes, grãos e rações. 2. ed. Curitiba: [s.n.], 148.

Leão, G. F. M., Pivatto, D. R. D., Carniel, H., Rodrigues, M. G. K., Braga, R. A., Silma, M. R. H. \& Teixeira, P. P. M. (2013). Melhoramento genético em zebuínos leiteiros - uma revisão. Agropecuária Científica no Semiárido. 9 (4), 09-14.

MAPA - Ministério da Agricultura, Pecuária e Abastecimento - Câmara Setorial da Cadeia Produtiva de Carne Bovina. Tuberculose e Brucelose. (2019) Brasília, DF. https://www.gov.br/agricultura/pt-br/assuntos/camaras-setoriais-tematicas/documentos/camaras-setoriais/carne-bovina/2019/53aro/pncebt_reuniao-camara-setorial-da-carne_11_04-convertido.pdf/@ @download/file/pncebt_reuniao-camara-setorial-da-carne_11_04.pdf

Martins, E. M., Santos, R. \& Junior, A. (2016). Cadernos técnicos de veterinária e zootecnia: Criação de bezerras leiteiras. Belo Horizonte: FEPMVZ.

Matos, A. T. (2007). Disposição de águas residuárias no solo. Viçosa: AEAGRI. 142 p. (Caderno Didático n. 38).

Matos, A. T. (2005). Curso sobre tratamento de resíduos agroindustriais. Departamento de Engenharia Agrícola e Ambiental / UFV. Fundação Estadual do Meio Ambiente.

Ministério da Saúde/SVS. (2021). Sistema de Informação de Agravos de Notificação - Sinan Net. Tuberculose - Casos confirmados e notificados no sistema de informação de agravos de notificação - Brasil. Rio Grande do Sul, RS.

Mauro, D. A. \& Silva, M. P. (2019). Métodos de destino final de animais mortos de médio e grande porte no Brasil. Comunicado Técnico EMBRAPA, v. 1.

Mota, C. A. (2013). Morfometria do placentomo da vaca mestiça holandês-zebu segundo a ordem de parto. Belo Horizonte, p. 47.

Moore, D. A., Merryman, M. L., Hartman, M. L. \& Klingborg, D, J. (2008). Comparison ofpublished recommendations regarding biosecurity practices for various production animal species and classes. JAVMA-J Am Vet Med Assoc. 233 (2), 249-256.

Nascente, E. P., Chagas, S. R., Pessoa, A, V, C., Matos, M, P, C., Andrade, M. A. \& Pascoal, L. M. (2019). Potencial antimicrobiano do ozônio: aplicações e perspectivas em medicina veterinária. Potencial antimicrobiano do ozônio, [S. 1.], p. 1-8. Potencial antimicrobiano do ozônio: aplicações e perspectivas em medicina veterinária (pubvet.com.br)

OMS - World Health Organization. One Health, (2017). https://www.who.int/news-room/q-a-detail/one-health

Otênio, M. H., Cunha, C. M. \& Rocha, B. B. (2010). Compostagem de carcaças de grandes animais. Embrapa Gado de Leite.

Oxaran, V., Lee, S. H. I., Chaul, L. T., Corassin, C. H., Barancelli, G. V., Alves, V. F., De Oliveira, C. A. F., Gram, L. \& De Martins, E. C. P. (2017). Listeria monocytogenes incidence changes and diversity in some Brazilian dairy industries and retail products. Food Microbiology, 68, 16-23.

Paul, R. \& Biagiotti, P. (2016). Construindo barreiras na fazenda leiteira. Revista Leite Integral. https://www.revistaleitei.ntegral.com.br/noticia/construindobarreiras-na-fazenda-leiteira

Pas Campo. (2005). Boas práticas agropecuárias na produção leiteira - Parte I-Brasília, DF : Embrapa Transferência de Tecnologia, 39 p. (Série Qualidade e segurança dos alimentos). Brasília, DF.

Pegoraro, L. M. C. (2019). A importância da biosseguridade na bovinocultura leiteira. $9^{o}$ Simpósio Brasil Sul de Bovinocultura de Leite.

Pegoraro, L. M. C., Weissheimer, C. F., Viegas, D. P., Pappen, F. G., Fischer, G., De Souza, G. N., Pradieé, J., De Almeida, L. L., Zanela, M. B., Saalfeld, M. H., Ribeiro, M. E. R., Dereti, R. M. \& Rodrigues, R. (2018). Biosseguridade na bovinocultura leiteira. ALICE. 
Pereira, M. L. (2017). Projeto ajudará a definir legislação e tecnologias para destinação de animais mortos. https://www.embrapa.br/busca-de-noticias//noticia/21280162/projeto-ajudara-a-definir-legislacao-e-te cnologias-para-destinacao-de-animais-mortos?link=agencia

Pohlmann, M. (2000). Levantamento de técnicas de manejo de resíduos da bovinocultura leiteira no estado de São Paulo. 115p. Dissertação (Mestrado de Engenharia Agrícola) - Universidade Estadual de Campinas. Faculdade de Engenharia Agrícola, Campinas. http://libdigi.unicamp.br/document/?code=vtls000219682

Pritchard, G. C. (1996). Added Animals: The challenge to preventive medicine. Cattle Practice 4, $253-257$.

Quintão, A. C. S. \& Galan, V. (2021). Panorama de mercado: IBGE aponta leve aumento da produção no primeiro Tri, mas cenário sinaliza queda em 2021. https://www.milkpoint.com.br/noticias-e-mercado/panorama-mercado/ibge-producao-de-leite-sinaliza- queda-em-2021-225456/

Rangel, A. H. N., Freire, R. M. B., Borba, L. H. F., Júnior, D. M. L. \& Novaes, L. P. (2015). Qualidade microbiológica da água utilizada em propriedades leiteiras. Revista do Instituto de Laticínios Cândido Torres, 70 (1).

Ribeiro, M. G., Geraldo, J. S., Langoni, H., Lara, G. H. B., Siqueira, A. K., Salerino, T. \& Fernandes, M. C. (2009). Microrganismos patogênicos, celularidade e resíduos de antimicrobianos no leite bovino produzido no sistema orgânico. Pesquisa Veterinária Brasileira, 29 (1) $52-58$.

Ricardo, A. N. T. (2016). Plano de manejo de resíduos de bovinocultura leiteira de uma propriedade rural no município de Santa Bárbara do Monte Verde, MG. Trabalho de Conclusão de Curso - Curso de Engenharia Ambiental e Sanitária, Universidade Federal de Juiz de Fora.

Rocha, M. A., Gouveia, A. M. G. \& Leite, R. C. (1999). Herpesvírus bovino tipo 1 no sêmen. Cienc. Rural. 29 (2), $373-380$.

Rupollo, G. (2003). Efeitos da umidade e do sistema de armazenamento na qualidade industrial de grãos de aveia. Dissertação (Departamento de Ciência e Tecnologia Agroindustrial) - Universidade Federal de Pelotas, [S. 1.].

Saalfeld, M. H. (2013). Silagem de colostro bovino: Propriedades e potencialidades de usos. Tese (Doutorado) - Programa de Pós Graduação em Biotecnologia. Universidade Federal de Pelotas, Pelotas- RS. f. 97.

Sachet, A. P., Baron, C. P., Franciscato, C. \& Firmino, A. S. (2013). Biossegurança em rebanhos leiteiros na agricultura familiar- Sudoeste paranaense. Archives of Veterinary Science. 18 (3).

Salman, A. K. D., Matarazzo, S. V., Arcaro Jr, I. \& Mello, D. S. (2020). Ambiência nas instalações para produção de leite. Embrapa: Pecuária Leiteira na Amazônia, cap. 9, p. 203-220. In: Salman, A. K. D.; Pfeifer, L. F. M.

Santos, R. (1999). Os Cruzamentos na Pecuária Tropical. Editora Agropecuária Tropical. 672 p.

Santos, R. (2007). O Gir e o Leite na pecuária fundamental. Editora Agropecuária Tropical. 456p.

Sayers, R. G., Sayers, G. P., MEE, J. F., Good, M., Bermingham, M. L., Grant, J. \& Dillon, P. G. (2013). Implementing biosecurity measures on dairy farms in Ireland. The Veterinary Journal. 197.

Schukken, Y. H., Grommer, F. J. \& Van der Geer, D. (1991). Risk factors for clinical mastitis in herds with low bulk milk somatic cell count. 2-Risk factors for Escherichia coli and Staphylococcus aureus. J. Dairy Sci., 74, 826-832.

Schultz, R. D., Hall, C. E. \& Sheffy, B. E. (1976). Current status of IBR/IPV virus infection in bulls. Proceedings of the United States Animal Health Association. 80, 159-168.

Sesti, L. (2004). Biosseguridade em granjas de frangos de corte: conceitos e princípios gerais. V Simpósio Brasil Sul de Avicultura.

Silva, L. F., Donald, A. C. A. P., Siebra, P. P., Machado, M. C. M., Gonçalves, C. S., Silva, A. C. A., Vasconcelos, A. B. \& Barros, I. O. (2020). The relevance of zoonoses epidemiological data and their unique health applicability. Braz. J. Hea. Rev., 3 (4), 10630-10634.

Sindicato das Indústrias de Laticínios no Estado de Goiás - SINDILEITE. (2016). Boas práticas agropecuárias. Goiânia - GO. $2^{\circ}$ edição.

Sperling, M.V. (2005). Introdução à Qualidade das Águas e ao Tratamento de Esgotos, v. 1, n. 3, Belo Horizonte: Departamento de Engenharia Sanitária e Ambiental; Universidade Federal de Minas Gerais.

Thomas, D. (1999). Venereal Diseases in the Bull. Bullish on Quality Beef, 71-76.

USDA - United States Department of Agriculture: National Agricultural Statistics Service. (2021). Milk Cows. https://www.nass.usda.gov/Charts_and_Maps/Milk_Production_and_Milk_Cows/milkcows.php

Vasconcellos, S. A. \& Ito, F. H. (2011). Principais Zoonoses transmitidas pelo leite - Atualização. Revista de Educação Continuada em Medicina Veterinária e Zootecnia do CRMV. 9 (1), 32-37.

Vieira, A. S., Mendes, G. H. O., Andrade, J. C. A. \& Santos, R A. (2014). Piquete Maternidade, volume (2), n. 7; Universidade Federal dos Vales do Jequitinhonha e Mucuri; Minas Gerais.

Weddle, D. B. (2017). Qual o risco? https://www.revistaleiteintegral.com.br/noticia/qual-o-risco

Zafalon, L. F.; Pozzi, C. R., De Campos, F. P., Arcaro, J. R. P., Sarmento, P. \& Matarazzo, S. V. (2008). Boas práticas de ordenha [recurso eletrônico]; ed 1. Embrapa Pecuária Sudeste, São Carlos. http://www.cppse.embrapa.br/servicos/publicacaogratuita/documentos/Documentos78.pdf/view 